\title{
THE USE OF TREFFTZ FUNCTIONS FOR APPROXIMATION OF MEASUREMENT DATA IN AN INVERSE PROBLEM OF FLOW BOILING IN A MINICHANNEL
}

\author{
Sylwia HOZEJOWSKA, Leszek HOZEJOWSKI •
}

\begin{abstract}
The paper is devoted to a computational problem of predicting a local heat transfer coefficient from experimental temperature data. The experimental part refers to boiling flow of a refrigerant in a minichannel. Heat is dissipated from heating alloy to the flowing liquid due to forced convection. The mathematical model of the problem consists of the governing Poisson equation and the proper boundary conditions. For accurate results it is required to smooth the measurements which was obtained by using Trefftz functions. The measurements were approximated with a linear combination of Trefftz functions. Due to the computational procedure in which the measurement errors are known, it was possible to smooth the data and also to reduce the residuals of approximation on the boundaries.
\end{abstract}

\section{INTRODUCTION}

The conducted experiment will be presented here only in brief, more detailed description can be found in [3],[4].The basic element of the experimental stand is a test section containing a minichannel with a refrigerant ( $R-123)$ flowing through it. One of the walls of the minichannel is a heating foil supplied with the direct current whose parameters can be controlled. Due to a layer of thermosensitive liquid crystals spread on the foil it is possible to observe (through a glass pane) changes in the foil surface hue. The back wall of the minichannel is kept in constant temperature. The quantities measured during the experiment are: local temperature of the heating foil, inlet and outlet liquid temperature and pressure, current and voltage drop of the electric power supplied to the heater. Velocity, pressure and inlet liquid subcooling do not change in the successive experiments. Wanted parameters include local heat transfer coefficients on the foil-liquid interface.

\section{Mathematical Model}

It is assumed that a process of heat conduction between the refrigerant and the twolayer partition is stationary. For simplicity of mathematical modelling, the investigations take into account only the dimension $x$ along the flow direction and the dimension $y$ along the thickness of foil (and glass).

According to these assumptions, the temperature satisfies the following equations

$$
\text { in glass: } \quad \nabla^{2} T_{G}=0
$$

\footnotetext{
- Sylwia Hozejowska, Kielce University of Technology, AL. 1000-lecia PP 7, 25-314 Kielce (Poland), e-mail: ztpsf@tu.kielce.pl,

Leszek Hozejowski, Kielce University of Technology, AL. 1000-lecia PP 7, 25-314 Kielce (Poland), e-mail: hozej@tu.kielce.pl
}

This is an Open Access article distributed under the terms of the Creative Commons Attribution License 2.0, which permits unrestricted use, distribution, and reproduction in any medium, provided the original work is properly cited. 


$$
\text { in foil: } \quad \nabla^{2} T_{F}=-\frac{q_{V}}{\lambda_{F}}
$$

where

$$
q_{V}=\frac{U \cdot I}{\delta_{F} \cdot W \cdot L}
$$

and $U$ - voltage drop $[\mathrm{V}], I$ - current $[\mathrm{A}], \delta_{F}$ - foil thickness $[\mathrm{m}], W$ - foil width $[\mathrm{m}]$, $L$ - foil length $[\mathrm{m}], \lambda_{F}$ - foil thermal conductivity $\left[\mathrm{Wm}^{-1} \mathrm{~K}^{-1}\right]$.

The conditions at the glass-foil contact can be written as

$$
\begin{gathered}
T_{F}\left(x_{k}, \delta_{G}\right)=T_{G}\left(x_{k}, \delta_{G}\right)=T_{k} \\
-\lambda_{F} \frac{\partial T_{F}}{\partial y}=-\lambda_{G} \frac{\partial T_{G}}{\partial y}, \quad y=\delta_{G}, 0 \leq x \leq L
\end{gathered}
$$

where $T_{k}$ denotes temperature measured at the glass-foil interface at discrete points $\left(x_{k}, \delta_{G}\right)$ by liquid crystals thermography $[2,3,4]$.

It is assumed that the remaining boundaries are isolated, see Fig. 1.

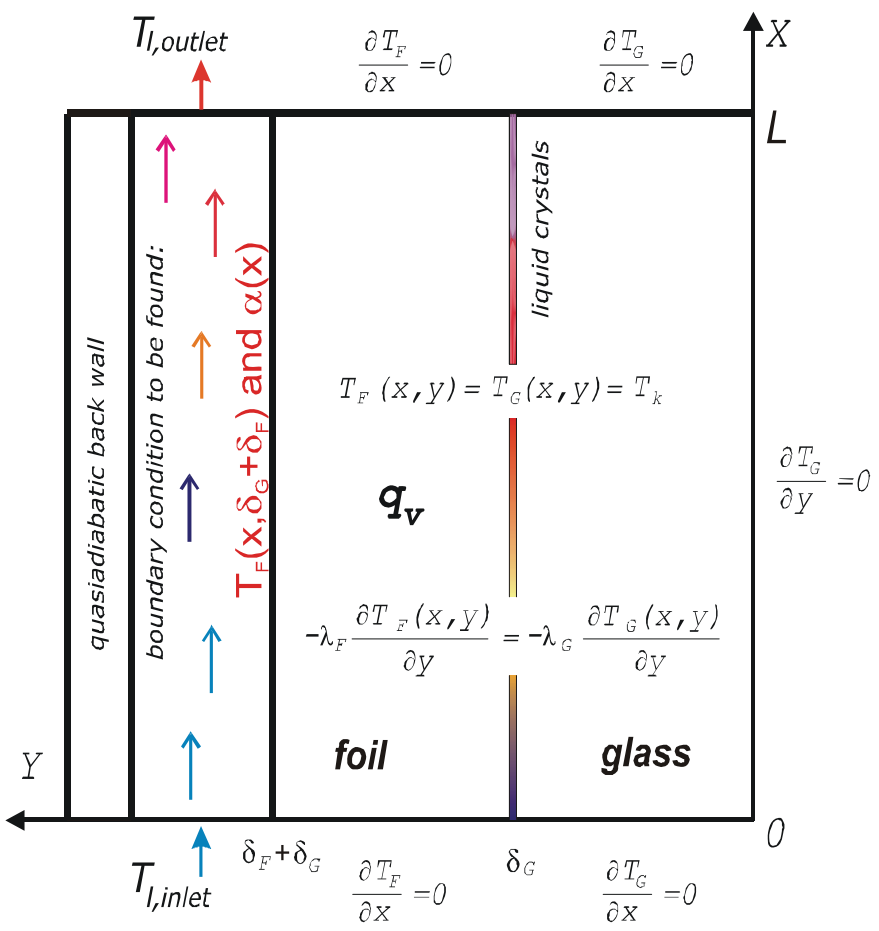

Figure 1. Diagram of flow boiling process in the investigated minichannel and boundary conditions

\section{Numerical Method (Trefftz Method)}

In the chosen method of computations, the unknown glass temperature $T_{G}$ and foil temperature $T_{F}$ are approximated with a linear combination of the Trefftz functions (shortly: T-functions) $u_{n}(x, y)$ which satisfy the eq. (1):

$$
T_{G}(x, y) \approx \sum_{i=0}^{N} a_{i} u_{i}(x, y)
$$




$$
T_{F}(x, y) \approx \widetilde{u}(x, y)+\sum_{j=0}^{M} b_{j} u_{j}(x, y)
$$

The function $\widetilde{u}(x, y)$ in (7) is any specific solution to eq.(2). The proper T-functions $u_{n}(x, y)$ are harmonic polynomials defined as a real and imaginary part, respectively, of $(x+i y)^{n}$. The series of T-functions starts with: $1, x, y, x y, \ldots$, and their properties are widely described in [1].

The unknown coefficients in (6) and (7), $a_{i}$ and $b_{j}$, are calculated so as to minimize the respective error functionals which represent mean square errors of temperature and heat flux approximations on boundaries of the considered region. In the first step of computations one minimizes the functional

$$
J_{G}=\left\|\frac{\partial T_{G}(x, 0)}{\partial y}\right\|^{2}+\left\|\frac{\partial T_{G}(L, y)}{\partial x}\right\|^{2}+\left\|T_{G}\left(x, \delta_{G}\right)-T_{\text {data }}(x)\right\|^{2}
$$

with $T_{\text {data }}(x)$ being temperature of the glass-foil interface. As suggested in [2] and [4], we take

$$
T_{\text {data }}\left(x_{k}\right)=T_{k}
$$

and consequently $T_{\text {data }}(x)$ appears in the functional (8) as a linear combination of T-functions

$$
T_{\text {data }}(x) \approx \sum_{i=0}^{P} c_{i} u_{i}\left(x, \delta_{G}\right)
$$

whose coefficients $c_{i}$ are chosen to satisfy the following condition

$$
\sum_{k=0}^{K}\left(T_{\text {data }}\left(x_{k}\right)-T_{k}\right)^{2} \rightarrow \min
$$

Since $T_{G}(x, y)$ has $a_{i}$ as coefficients of expansion in a series of harmonic polynomials then $a_{i}$ are obtained from the system of equations

$$
\frac{\partial J_{G}}{\partial a_{i}}=0, i=0,1, \ldots, \mathrm{N}
$$

In the same manner, by minimizing functional $J_{F}$, we evaluate the coefficients $b_{j}$ which appear in formula (7) defining $T_{F}(x, y)$. Having known the temperature $T_{F}(x, y)$ on the boundary $y=\delta_{G}+\delta_{F}$ we can compute the heat transfer coefficient $\alpha$ from the third kind boundary condition

$$
-\lambda_{F} \frac{\partial T_{F}\left(x, \delta_{G}+\delta_{F}\right)}{\partial y}=\alpha(x)\left(T_{F}\left(x, \delta_{G}+\delta_{F}\right)-T_{l}(x)\right)
$$

where fluid temperature $T_{l}(x)$ changes, for simplicity, linearly from $T_{l, \text { inlet }}$ to $T_{l, \text { outlet }}$.

\section{Modification of Numerical Method}

In the method described above, the boundary condition (4) is not fulfilled in a strict sense. Residuals $T_{G}\left(x_{k}, \delta_{G}\right)-T_{\text {data }}\left(x_{k}\right)$ are assumed to have normal distribution of the mean value 0 and the variance $\sigma_{k}^{2}$. Errors $\sigma_{k}$ are obtained from the calibration curve determining the relationship between the foil temperature and the liquid crystals hue. The $\sigma_{k}$ value reflects the error of heat foil temperature estimation based on the hue indicated by liquid crystals, [2]. In functionals $J_{G}$ and $J_{F}$, the last components 
$\left\|T_{G}\left(x, \delta_{G}\right)-T_{\text {data }}(x)\right\|^{2}$ and $\left\|T_{F}\left(x, \delta_{G}\right)-T_{\text {data }}(x)\right\|^{2}$ are responsible for accuracy of approximate fulfilment of condition (4).

After modification of $J_{G}$ and $J_{F}$, the last components will take on the respective forms:

$$
\begin{gathered}
\text { for glass: }\left\|\frac{T_{G}\left(x_{k}, \delta_{G}\right)-T_{\text {data }}\left(x_{k}\right)}{\sigma_{k}}\right\|^{2} \\
\text { for foil: }\left\|\frac{T_{F}\left(x_{k}, \delta_{G}\right)-T_{\text {data }}\left(x_{k}\right)}{\sigma_{k}}\right\|^{2}
\end{gathered}
$$

The purpose of modification is to provide residuals $T_{G}\left(x_{k}, \delta_{G}\right)-T_{\text {data }}\left(x_{k}\right)$ with such weights, $\left(\sigma_{k}\right)^{-2}$, that the smaller error of individual measurement $T_{k}$ we have, the greater weight is ascribed to it in further calculations.

\section{Results And Discussion}

The values of heat transfer coefficient are derived from experimental data presented in Fig.2 and containing hue distributions on the foil external surface (obtained through liquid crystal thermography). The specific solution of eq. (2) is chosen in the form $\widetilde{u}(x, y)=-0.5 q_{v} \lambda_{F}^{-1} y^{2}$.

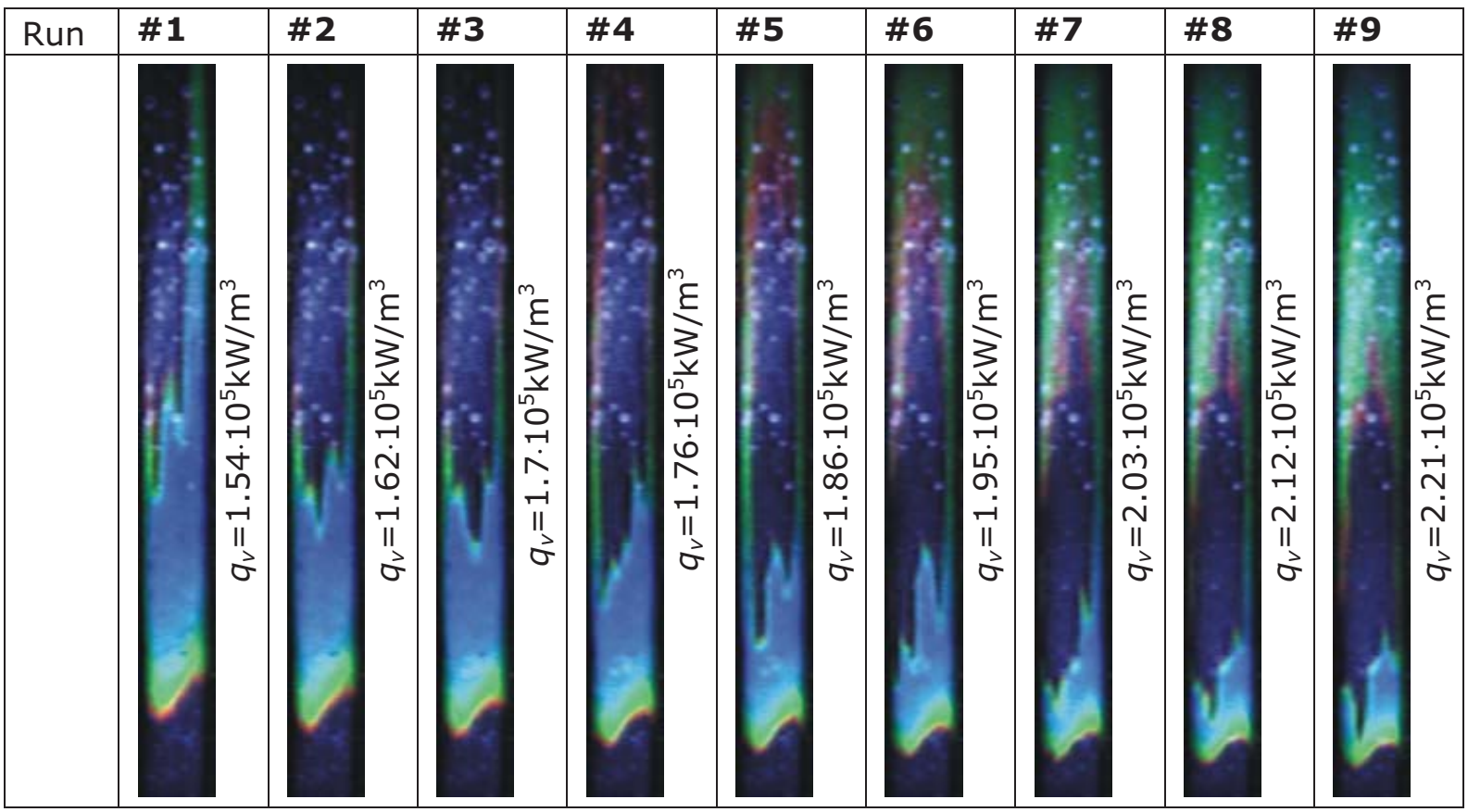

Figure 2. Hue distribution on the minichannel external surface while increasing the heat flux supplied to the heating foil. Parameters of the runs: $G=223$ $\mathrm{kg} /\left(\mathrm{m}^{2} \mathrm{~s}\right) ; \operatorname{Re}=1361 ; p_{\text {inlet }}=302 \mathrm{kPa}$; foil parameters: $\delta_{F}=1.02 .10^{-4} \mathrm{~m}, W=$ $0.08 \mathrm{~m}, L=0.28 \mathrm{~m}, \lambda_{G}=8.3 \mathrm{~W} /(\mathrm{mK})$; glass parameters: $\delta_{G}=0.005 \mathrm{~m}, \lambda_{G}=0.71$ $\mathbf{W} /(\mathbf{m K})$ 
For expected improvement of accuracy, temperature of the glass-foil interface $T_{\text {data }}(x)$ was approximated with a linear combination of T-functions and the results are presented in Fig.3
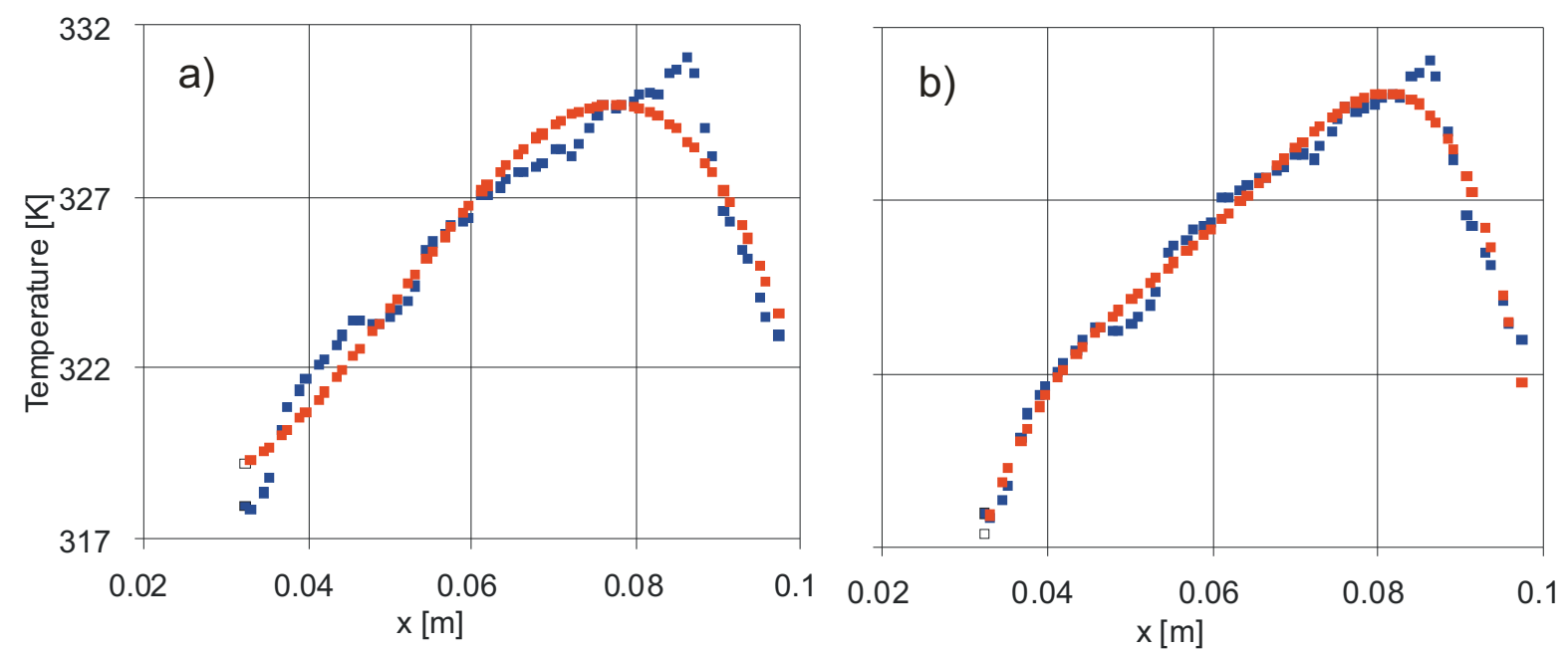

Figure 3. Temperature (obtained in run \# 3): measured $T_{k}(\diamond \bullet)$ and calculated $T_{\text {data }}(x)(\diamond)$ ). a) The number of T-functions $=6, \mathbf{R}^{2}=0.97 ;$ b) The number of T-functions = 8, $R^{2}=0.99 ;\left(R^{2}-\right.$ coefficient of determination $)$

The function $T_{\text {data }}(x)$ smoothed the measurement data, as shown in Fig 3. In comparison with classical Trefftz method, (see [1], [2] and [3]), after modification of $J_{G}$ and $J_{F}$ the computed temperatures $T_{G}$ and $T_{F}$ satisfy the boundary conditions (4) and (5) with a smaller mean square error. For example, in case of the data from run\#3 we have $\left\|T_{G}\left(x_{k}, \delta_{G}\right)-T_{\text {data }}\left(x_{k}\right)\right\|=0.73 \mathrm{~K} \quad$ and $\quad\left\|T_{F}\left(x_{k}, \delta_{G}\right)-T_{\text {data }}\left(x_{k}\right)\right\|=0.71 \mathrm{~K}$ and also $\left\|T_{G}\left(x_{k}, \delta_{G}\right)-T_{k}\right\|=0.84 \mathrm{~K} \quad$ and $\left\|T_{F}\left(x_{k}, \delta_{G}\right)-T_{k}\right\|=0.82 \mathrm{~K}$. The approximates of temperatures $T_{G}$ and $T_{F}$ fulfil the boundary condition (5) with similar accuracy. Numerical experiments proved that the number of T-functions in expansion (6) should be the same as in expansion (7), otherwise the final results may be less accurate. In further computations it was sufficient to take $M=N=8$. To point out the other advantages of modification described in paragraph 4, one should notice a decrease of the difference between temperatures of glass and foil at the glass-foil interface. Except for run \# 1 and run \#2 a decrease of the value of $\left\|T_{G}\left(x, \delta_{G}\right)-T_{F}\left(x, \delta_{G}\right)\right\|$ was significant, e.g. from $0.52 \mathrm{~K}$ to $0.09 \mathrm{~K}$ in case of run \#3 or from $0.85 \mathrm{~K}$ to $0.01 \mathrm{~K}$ in case of run \#7. Moreover, after modification of Trefftz method, the computations included linear systems which are better-behaved as far as ill-conditioning is concerned. 

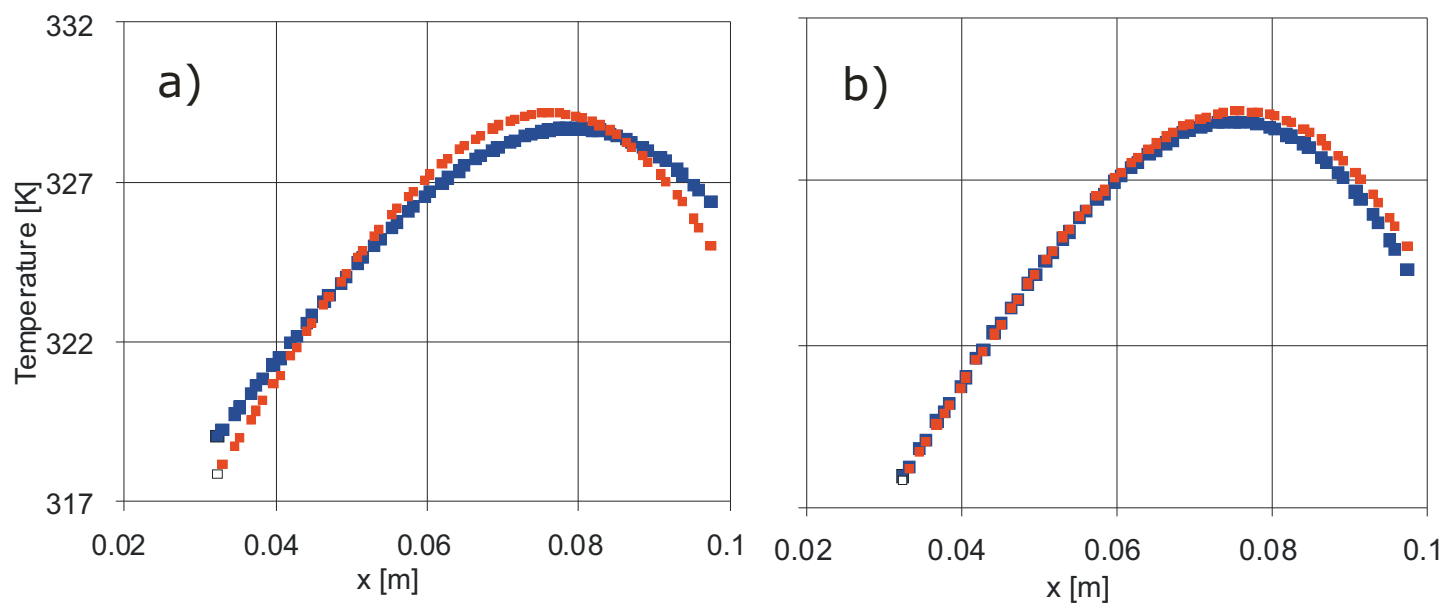

Figure 4. Glass temperature $T_{G}(\diamond \bullet \bullet)$ and foil temperature $T_{F}(\diamond \bullet \bullet)$ on the glass-foil interface (run \# 3). Computed with a) Trefftz method, b) modified Trefftz method

The computed heat transfer coefficient obtained with modified Trefftz method (see Fig.5) is insignificantly larger when compared to that obtained with classical Trefftz method and, additionally, a minimum in the curve representing its variation is more distinctive.

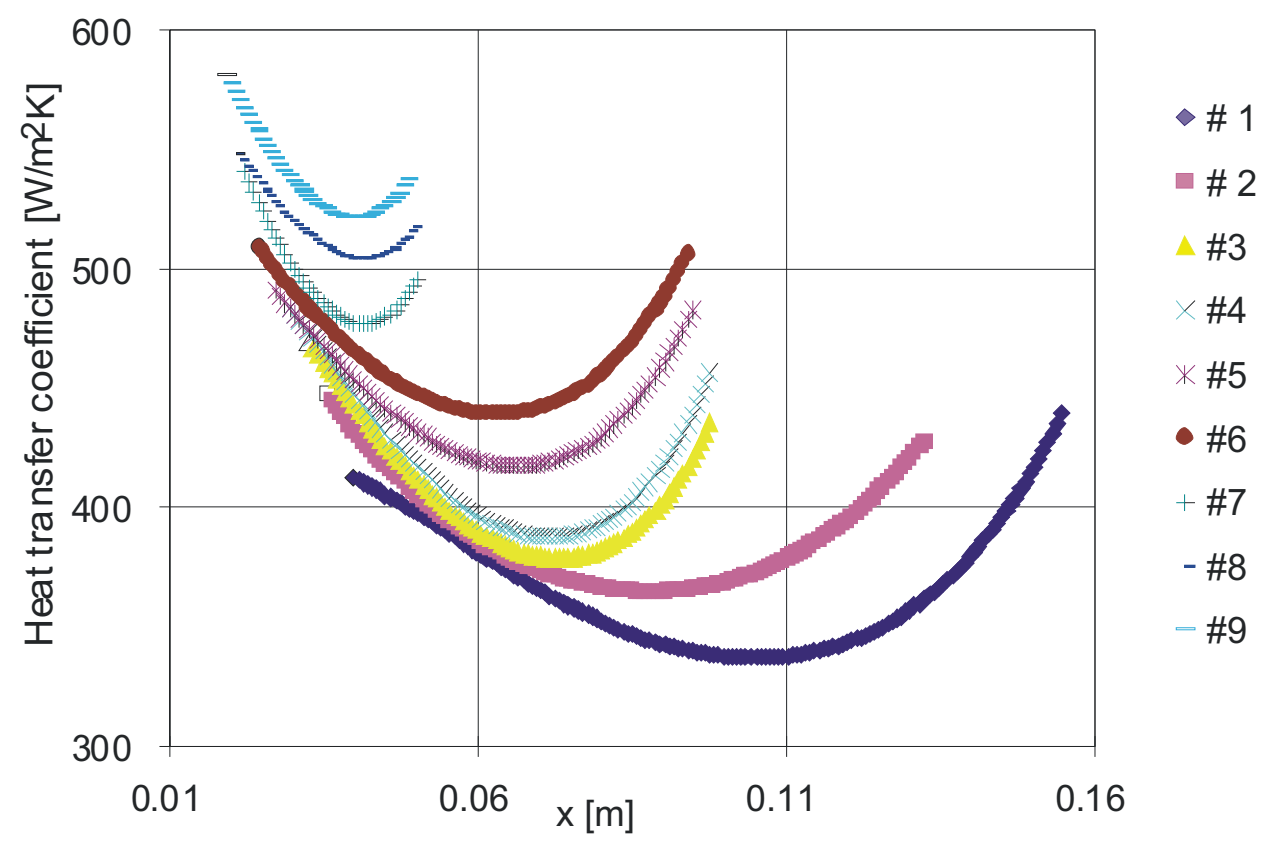

Figure 5. Local heat transfer coefficients computed with modified Trefftz method.

\section{Conclusion}

The following conclusions can be drawn:

1. Approximation of temperature measurements with a use of T-functions in the discussed problem resulted in smoothing the measurement data and better fulfilment of prescribed boundary conditions.

2. For most accurate results in case of a compound body, the numbers of T-functions in approximations of temperature in each subdomain should be equal. 
3. Application of measurement errors for a modification of Trefftz method allowed to reduce the differences between the computed temperatures of glass and foil at the interface between them.

4. The proposed modification of Trefftz method did not substantially influence the values of the local heat transfer coefficient, however the changes in its graph better fit the purpose of finding the "boiling front" area.

\section{REFERENCES}

[1] Cialkowski M. and Frackowiak A., Heat functions and their application to solving heat conduction and mechanical problems (in Polish), Poznan, Poznan Univ. of Technology, 2000

[2] Hozejowska S., Piasecka M., Poniewski M.E., Boiling heat transfer in vertical minichannels. Liquid crystal experiments and numerical investigations, Int. J. of Thermal Sciences, 48, pp.1049-1059, 2009

[3] Piasecka M., Experimental investigation on flow boiling heat transfer in minichannels of different spatial orientations, Liberec, Proc. Experimental Fluid Mechanics, pp.290-303, 2009

[4] Piasecka M., Hozejowska S., Poniewski M.E., Experimental evaluation of flow boiling incipience of subcooled fluid in a narrow channel, Int. J. Heat \& Fluid Flow, 25, pp.159-172, 2004 